\title{
Factors associated with alcohol consumption patterns in a Puerto Rican urban cohort
}

\author{
Johanna Y Andrews-Chavez ${ }^{1}$, Christina S Lee ${ }^{2}$, Robert F Houser ${ }^{1}$, Luis M Falcon ${ }^{3}$ and \\ Katherine L Tucker ${ }^{4}$ * \\ ${ }^{1}$ Friedman School of Nutrition Science and Policy, Tufts University, Boston, MA, USA: ${ }^{2}$ Counseling \& Applied \\ Educational Psychology, Northeastern University, Boston, MA, USA: ${ }^{3}$ Office of the Dean Fine Arts, Humanities and \\ Social Sciences, University of Massachusetts Lowell, Lowell, MA, USA: ${ }^{4}$ Department of Clinical Laboratory and \\ Nutritional Sciences, University of Massachusetts Lowell, 3 Solomont Way, Suite 4, Lowell, MA 01854, USA
}

Submitted 20 June 2013: Final revision received 25 February 2014: Accepted 3 March 2014: First published online 8 April 2014

\begin{abstract}
Objective: There is little research on factors associated with alcohol consumption among Puerto Ricans living in the USA; thus the aim of the present study was to examine alcohol intake patterns, and factors associated with drinking categories, in a cohort of Puerto Rican adults in Massachusetts.

Design: Cross-sectional study. Descriptive and polytomous logistic regression analyses were used to identify factors associated with drinking patterns, stratified by gender.

Setting: Greater Boston area, MA, USA.

Subjects: Puerto Rican adults ( $n$ 1292), aged $45-75$ years.

Results: Eight per cent of men and $39 \%$ of women were lifetime abstainers; $40 \%$ of men and $25 \%$ of women were former drinkers; $31 \%$ of men and $27 \%$ of women were moderate drinkers; and $21 \%$ of men and $8 \%$ of women were heavy drinkers. Thirty-five per cent of participants reported drinking alcohol while taking medications with alcohol contraindications. After multivariable adjustment, young men were less likely than older men to be moderate drinkers. Among women, higher BMI, age, lower income and lower psychological acculturation were associated with abstention; age and lower perceived emotional support were associated with increased likelihood of former drinking; and women without $v$. with diabetes were more likely to be heavy drinkers.

Conclusions: High prevalence of chronic disease, heavy drinking and alcohol use while taking medications with alcohol contraindications suggest an urgent need for better screening and interventions tailored to this rapidly growing Hispanic national subgroup. As heavy drinking appears to increase with acculturation for women, public health initiatives are needed to support appropriate alcohol use.
\end{abstract}

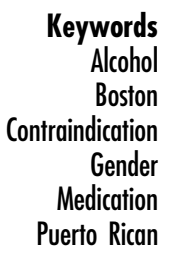

According to the WHO, nearly $4 \%$ of deaths and almost $5 \%$ of the global burden of disease and injury are related to alcohol $^{(1)}$. In the USA excessive alcohol use is the third leading lifestyle-related cause of death, with approximately 79000 deaths per annum attributable to alcohol $u^{(2)}{ }^{(2)}$. The most recent National Survey on Drug Use and Health found that half of Americans aged 12 years or older were current drinkers. Heavy drinking, defined as more than one drink per day for women and more than two drinks per day for men, was reported in almost $7 \%$ of people aged 12 years and older ${ }^{(3,4)}$. In the USA, nonHispanic whites, Native Americans and Hispanics are more likely than African Americans or Asian Americans to use alcohol $^{(5)}$.

Alcohol misuse by older adults is a growing public health concern $^{(6)}$. Excessive drinking has consequences on nearly every part of the body ${ }^{(5)}$ and drinking has been increasing in this age group, particularly since $1995^{(7)}$. There are particular health and medical risks associated with alcohol misuse at older age. A report presented at the Expert Conference on Alcohol and Health found that 'biological changes associated with aging and the use of medications heighten elderly peoples' susceptibility to the negative effects of alcohol ${ }^{(8)}$. Long-term heavy drinking increases risk for high blood pressure, heart rhythm irregularities, heart muscle disorders and stroke ${ }^{(8,9)}$. Furthermore, it increases the risk of developing certain forms of cancer (e.g. oesophagus, mouth, throat and larynx) and can increase the risk for developing cancer of the colon and rectum. Moreover, it may increase women's risk of developing breast cancer. Many cases of memory deficits and dementia are considered to result from high 
alcohol consumption ${ }^{(10)}$. On the other hand, there is accumulating evidence that moderate alcohol consumption may serve as a protective factor against diseases such as CHD, ischaemic stroke and osteoporosis ${ }^{(11,12)}$. However, the cardioprotective effect is reversed with heavier drinking.

Older adults with multiple medical conditions are particularly vulnerable to negative physical consequences due to their alcohol use ${ }^{(13)}$. As adults with multiple illnesses usually take numerous medications at once, they may be at risk for hospitalization due to adverse alcohol-drug interactions. Numerous classes of prescription medications can interact with alcohol, including 'antibiotics, antidepressants, antihistamines, barbiturates, benzodiazepines, histamine $\mathrm{H} 2$ receptor antagonists, muscle relaxants, nonnarcotic pain medications and anti-inflammatory agents, opioids, and warfarin', $^{, 14}$

Most research on patterns and predictors of alcohol consumption among Hispanics comes from studies with Mexican Americans in the west and south-west USA, and few have focused on alcohol use rates among the older population. In the present paper we report data from the Boston Puerto Rican Health Study (BPRHS), a longitudinal cohort study of older Puerto Ricans residing in the Boston metropolitan area. Our study contributes to the growing need for alcohol research focused on other Hispanic nationalities, such as Puerto Ricans, who are more highly represented in the north-eastern USA than in other parts of the country. A higher prevalence of alcohol misuse and related problems for Puerto Ricans has been documented relative to other Hispanic groups ${ }^{(15-21)}$. However, little is known about the factors associated with drinking patterns among Puerto Ricans residing in the USA. The primary purpose of our study was to examine the prevalence of drinking in older Puerto Rican adults, the sociodemographic and health characteristics of participants in each drinking category and the prevalence of drinking among participants taking medications with alcohol contraindications.

\section{Methods}

\section{Study population}

We used data from the BPRHS cohort, a large group of middle-aged and older adults recruited throughout the Boston metropolitan area. The original cohort consists of approximately 1500 Puerto Rican adults. For the original study, data from the 2000 census helped identify census blocks with at least twenty-five Hispanic adults aged 45-75 years. Within these census blocks, randomly selected blocks with at least ten Hispanics fitting the age criteria were enumerated, and one self-identified Puerto Rican from each household was randomly invited to participate in the study. Although the majority of participants were recruited through door-to-door enumeration (77\%), a small portion of the cohort was recruited during community fairs and events (10\%), referrals (7\%) and calls to the study office $(6 \%)$. As with most epidemiological studies, selection bias could occur. For example, individuals declining study participation may be more acculturated than those participating. However, comprehensive protocols were put in place to expand recruitment with various community-based strategies and the final sample includes a large percentage (15\%) of the population of Puerto Ricans in this age range living in urban neighbourhoods in the Boston area. Detailed sampling and recruitment methods have been published previously ${ }^{(22)}$. Participants completed a comprehensive set of baseline questionnaires and tests between 2004 and 2009 and received monetary compensation for their time ${ }^{(22)}$. A total of 1292 participants with complete questionnaires were included in our analysis.

The study was conducted according to the guidelines laid down in the Declaration of Helsinki. The Institutional Review Board at the Tufts Medical Center approved all procedures involving human subjects. Written consent was obtained from all participants in their language of preference before participating in the study. Permission to use the data was granted by the Institutional Review Board at Northeastern University.

\section{Measurements}

\section{Alcohol}

The National Institute on Alcohol Abuse and Alcoholism (NIAAA) defines heavy drinking as 'more than 4 drinks on any single day or more than 14 drinks per week for men' or 'more than 3 drinks on any single day or more than 7 drinks per week for women'(23). Previously in this cohort $^{(22)}$, moderate drinking was defined as less than or equal to $1 \mathrm{drink} /$ day for women or less than or equal to 2 drinks/day for men' and heavy drinking as 'more than 6 drinks during one day of drinking, or more than 1 drink/ day for women or more than 2 drinks/day for men'. In the present analysis, the NIAAA criterion for heavy drinking yielded a higher number of heavy drinkers than the earlier BPRHS analysis ${ }^{(22)}$, because it was gender adjusted - the BPRHS used a cut-off of 6 drinks/d, rather than 4 drinks/d for men or 3 drinks/d for women. More details on the NIAAA's definition can be found online (http://www.niaaa.nih.gov/ alcohol-health/overview-alcohol-consumption/moderatebinge-drinking).

The current study, a secondary analysis of the original BPFHS, used the same items about alcohol use used previously in the Massachusetts Hispanic Elderly Study (MAHES) and in the National Health and Nutrition Examination Survey (NHANES) $^{(24,25)}$. The alcohol-consumption measures were derived from questions in the alcohol section of the baseline interview. Participants were asked about the history, quantity and frequency of alcohol consumed. The questions were: 'Have you had at least 12 drinks of any kind of alcohol during your life?'; 'Presently, do you drink alcohol?'; 'For how many years did you drink alcohol'; and 'On average, how often do 
you drink any type of alcohol?'. The unit of measurement for drinking frequency was days per week, per month or per year. Drinking frequencies were recoded to reflect weekly frequency. For the daily consumption we used the question: 'On average, on the days that you drink alcohol, how many drinks do you have a day? By a drink, I mean a 12-oz beer, 4-oz glass of wine, or an ounce of liquor'. The unit of measurement for daily consumption was drinks/d.

Participants were placed into one of four categories: (i) lifetime abstainer (LA); (ii) former drinker (FD); (iii) moderate drinker (MD); or (iv) heavy drinker (HD). To be considered a lifetime abstainer, respondents had to indicate that they had fewer than 12 drinks in their lifetime. To be considered a former drinker, respondents had to indicate that they had more than 12 drinks in their lifetime, but that they did not currently drink. To be considered a moderate drinker, a man had to indicate that he consumed $\leq 14$ drinks/week and $\leq 4$ drinks/d. For a woman to be considered a moderate drinker, she had to indicate that she consumed $\leq 7$ drinks/week and $\leq 3$ drinks/d. Male respondents indicating that the number of drinks/week was $>14$, or that the number of drinks/d was $>4$, were classified as heavy drinkers. Female respondents indicating that the number of drinks/week was $>7$, or that the number of drinks/d was $>3$, were classified as heavy drinkers. The moderate drinking category was used as the reference group in the analyses.

\section{Independent variables}

We investigated variables that may be related to alcohol use, including the following.

Demographic characteristics. Demographic characteristics included age, gender and education level (recoded into three categories: elementary/middle (less than 9th grade); high school (some high school 9th-12th grade); and postsecondary (some college/graduate)). Marital status was coded as either married or unmarried (divorced, widowed and never married were grouped in the unmarried category). Income was calculated as the sum of household income, including that from the Temporary Assistance for Needy Families Program (TANF), Supplementary Security Income (SSI), Social Security Disability Insurance (SSDI), child support, pension, retirement and the Supplementary Nutrition Assistance Program (SNAP). Employment status was coded as either currently working or currently not working. Language preference was recoded from five categories into three categories (English only, Spanish only or both equally). Living situation was coded as either living alone or not living alone.

Health characteristics. BMI was calculated as weight in kilograms divided by the square of height in metres. Overweight was defined as $\mathrm{BMI} \geq 25 \mathrm{~kg} / \mathrm{m}^{2}$. Smoking status was classified as never ( $<100$ cigarettes in lifetime), former (>100 cigarettes in lifetime, but currently not smoking) or current smoker. Diabetes (yes $v$. no) was defined as fasting blood glucose $\geq 126 \mathrm{mg} / \mathrm{dl}$ or taking diabetes medication. Hypertension (yes $v$. no) was defined as systolic blood pressure $\geq 140 \mathrm{mmHg}$ or diastolic blood pressure $\geq 90 \mathrm{mmHg}$ or taking hypertension medications. Contraindicated medications use was defined as taking medications with alcohol contraindication or not, including at least one of the following four classes: anticonvulsants, antidepressants, antipsychotics and anxiolytics. Emotional support was a continuous variable (range 2-256) used to evaluate emotional and tangible (functional) support. Participants identified important persons in their life and indicated their perception of how these important persons could support them emotionally or assist them in time of need. The Psychological Acculturation Scale (PAS) measures the level of comfort participants have with Anglo culture relative to Puerto Rican culture. It has a range of 10-50, from less acculturated to more acculturated ${ }^{(22)}$. Depressive symptomology (presence of depressive symptoms) was evaluated using the abbreviated ten-item Center for Epidemiological Studies Depression Scale (CESD) score $\geq 16^{(26)}$. Perceived health status was recoded from five self-rated health status categories (excellent, very good, good, fair, poor) to two categories (excellent/good or fair/poor).

\section{Statistical analyses}

For some variables, categories were aggregated into larger categories if their cell numbers were too low to be statistically meaningful (e.g. those divorced were grouped together with widowed; college graduates with those with some graduate school training; only Spanish speakers with mostly Spanish speakers; the same was done for English speakers). We divided income by 1000 , and emotional support score by 10 , to make the regression coefficients easier to interpret. A medications variable was created to indicate participants on medications with alcohol contraindications, including anticonvulsants, antidepressants, antipsychotics and anxiolytics.

Statistical analyses were performed using the Stata IC statistical software package, version $12 \cdot 1$. Descriptive analyses were performed to characterize the total sample and to calculate the number of participants in each alcohol category. A multinomial (polytomous) logistic regression model with a four-level alcohol status measure as the dependent variable (LA, FD, MD, HD) was used for the present study. Polytomous logistic regression simultaneously estimates binary logistic regression models for multiple outcomes of a nominal variable. In multinomial analyses, one outcome category is selected as the reference category and the choice does not alter the results. In these models, the effect of each variable can be assessed holding other variables in the model constant. The 'moderate drinking' outcome category was used as the reference group in the polytomous analyses. Confidence intervals were measured at the $95 \%$ significance level and a $P$ value of 0.05 or less was considered to be significant. 


\section{Results}

\section{Demographic characteristics}

The majority $(>70 \%)$ of both men and women in the sample had completed some high school. About half of the LA, FD and MD men were married, while $40 \%$ of HD men were married. The majority of both men and women were unemployed or no longer working (>60\%). Spanish was the preferred language among both genders and all drinking groups. About $30-40 \%$ of men and women lived alone.

A total of 407 (39\%) women and thirty-five (8\%) men reported lifetime alcohol abstinence (Table 1). A greater percentage of men than women reported being FD ( $40 \%$ and $25 \%$, respectively). Twenty-seven per cent of women and $31 \%$ of men were MD. Men were far more likely to report being a HD (21\%) than women (8\%).

HD men tended to be younger (mean age 54.7 (SD 6.9) years) than men in the other drinking categories (mean age: LA, 55.9 (sD 8.3) years; FD, 57.2 (sD 7.9) years; MD, 56.7 (sD $8 \cdot 1$ ) years). The age difference across women was larger, ranging from 53.4 (SD 5.5) years for HD to 58.5 (SD $7 \cdot 7$ ) years for LA.

\section{Health characteristics}

The majority $(>75 \%)$ of both men and women were overweight or obese. The mean BMI was greater for women $\left(32.6(\mathrm{sD} 6 \cdot 8) \mathrm{kg} / \mathrm{m}^{2}\right.$ ) than for men (29.5 (SD 5.3) $\mathrm{kg} / \mathrm{m}^{2}$ ). HD had the lowest average BMI compared with the other drinking categories for both genders (Table 2). FD and MD men were less likely to smoke than LA or HD men. For women, LA, FD and MD were less likely to be current smokers, compared with HD. The FD group had the largest proportion of participants with diabetes and hypertension, for both genders. Among all participants, antidepressants were the most commonly taken medications with alcohol contraindications (between 20 and $33 \%$ of men and between 34 and $51 \%$ of women were taking antidepressants). Among men, $32 \%$ of MD and $28 \%$ of HD reported taking at least one or more of the medication regimens with alcohol contraindications. For women, $44 \%$ of MD and almost $59 \%$ of HD reported taking at least one or more medication regimens with alcohol contraindications. For men, LA and MD reported the highest emotional support scores (score $=76$ ) and HD the lowest (score $=67$ ). For women, FD and HD reported the lowest emotional support scores (score $=73$ ) while MD reported the highest (score $=88$ ). For both the men and the women in the study, LA reported the lowest acculturation (PAS score $=17 \cdot 1$ and $16 \cdot 8$, respectively) while MD reported the highest (PAS score $=20 \cdot 2$ and $19 \cdot 4$, respectively). For men, LA had the largest proportion (49\%) of participants with high depressive symptomatology (score $\geq 22$ ) and MD had the lowest proportion ( $27 \%$ ). For women, MD also had the lowest proportion of participants with high depressive symptomatology (44\%) while FD had the highest (57\%).
The majority of participants in both genders rated their health status as fair/poor.

Thirty-five per cent of the participants drank alcohol while taking medications with an alcohol contraindication (Table 3, $n$ 687). Almost $33 \%$ of women on these medications drank alcohol, while $44 \%$ of the men on these medications were drinking $(P<0 \cdot 01 ;$ Fig. 1$)$. A greater proportion of employed participants drank while they were taking medications with alcohol contraindications compared with their unemployed counterparts (50\% of employed $v$. 36\% of unemployed, $P<0.05)$. Almost $61 \%$ of English speakers who were taking medication regimens with alcohol contraindications consumed alcohol, while $36 \%$ of Spanish speakers and $27 \%$ of bilingual participants did $(P<0 \cdot 001)$. A greater proportion of participants without diabetes (39\%) drank alcohol while taking medications with alcohol contraindications, compared with those with diabetes $(32 \% ; P<0.05)$.

\section{Multinomial logistic regression models}

The multinomial logistic regression analyses included 1292 participants with complete information on the variables of interest. With greater age, men were less likely to be LA (relative risk ratio $(\mathrm{RRR})=0.92 ; 95 \% \mathrm{CI} 0.86,0.98)$ or $\mathrm{HD}$ $(\mathrm{RRR}=0.94 ; 95 \%$ CI 0.90, 0.98) than MD (Table 4, $n$ 381). In contrast, older $v$. younger women were more likely to be LA $(\mathrm{RRR}=1.03 ; 95 \% \mathrm{CI} 1.00,1.06)$ or FD $(\mathrm{RRR}=1.04 ; 95 \% \mathrm{CI}$ $1.01,1.07$ ) than MD (Table $5, n$ 911). In addition for women, higher income was associated with lower prevalence of LA $(\mathrm{RRR}=0.98 ; 95 \% \mathrm{CI} 0.96,1.00)$ or FD (RRR $=0.98 ; 95 \% \mathrm{CI}$ 0.97, 0.99) than MD; higher emotional support score was associated with lower prevalence of FD than MD (RRR = 0.94; $95 \%$ CI 0.90, 0.99); higher PAS score was associated with lower prevalence of LA than MD $(\mathrm{RRR}=0.95 ; 95 \% \mathrm{CI}$ 0.92, 0.98); and higher BMI was associated with higher prevalence of $\mathrm{LA}$ than $\mathrm{MD}(\mathrm{RRR}=1 \cdot 04 ; 95 \% \mathrm{CI} 1 \cdot 01,1 \cdot 07)$.

\section{Discussion}

Approximately $21 \%$ of men and $8 \%$ of women in this Puerto Rican urban cohort reported alcohol intake in excess of NIAAA guidelines. Older men were more likely to be moderate drinkers than heavy drinkers or lifetime abstainers. Older women were more likely to be abstainers or former drinkers, while younger women were more likely to be moderate or heavy drinkers. Thirty-five per cent of the participants drank alcohol while taking medications with an alcohol contraindication. Given the high proportion of participants who reported exceeding the recommended drinking limits and drinking when taking contraindicated medications, there seems to be value for additional targeted approaches within the health-care setting in this population ${ }^{(27,28)}$.

The high prevalence of heavy drinking among men in this cohort is in line with previous studies showing that men are more likely to drink than women and that they 
Table 1 Descriptive demographic characteristics by drinking status among Puerto Rican adults ( $n$ 1472) aged 45-75 years from the Boston Puerto Rican Health Study (BPRHS) cohort, 2004-2009

\begin{tabular}{|c|c|c|c|c|c|c|c|c|c|c|c|c|c|c|c|c|}
\hline & \multicolumn{16}{|c|}{ Drinking status } \\
\hline & \multicolumn{8}{|c|}{ Men } & \multicolumn{8}{|c|}{ Women } \\
\hline & \multicolumn{2}{|c|}{ LA $(n$ 35)† } & \multicolumn{2}{|c|}{ FD $(n$ 174)‡ } & \multicolumn{2}{|c|}{$\mathrm{MD}(n 134) \S$} & \multicolumn{2}{|c|}{$\mathrm{HD}(n$ 93)\| } & \multicolumn{2}{|c|}{ LA $(n$ 407)ף } & \multicolumn{2}{|c|}{ FD (n 261)†† } & \multicolumn{2}{|c|}{ 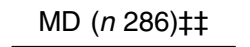 } & \multicolumn{2}{|c|}{$\mathrm{HD}(n$ 82)§§ } \\
\hline & $n$ & $\%$ & $n$ & $\%$ & $n$ & $\%$ & $n$ & $\%$ & $n$ & $\%$ & $n$ & $\%$ & $n$ & $\%$ & $n$ & $\%$ \\
\hline $\begin{array}{l}\text { Age (years)||II } \\
\text { Education }\end{array}$ & $55 \cdot 9$ & $8 \cdot 3$ & $57 \cdot 2$ & $7 \cdot 9$ & $56 \cdot 7$ & $8 \cdot 1$ & $54 \cdot 7$ & $6 \cdot 9$ & 58.5 & $7 \cdot 7$ & 58.0 & $7 \cdot 4$ & $55 \cdot 9$ & $7 \cdot 0$ & $53 \cdot 4$ & $5 \cdot 5$ \\
\hline Elementary/middle & 20 & $57 \cdot 1$ & 81 & 46.5 & 51 & 38.6 & 39 & 41.9 & 226 & 55.5 & 114 & 43.9 & 116 & 40.5 & 37 & $45 \cdot 1$ \\
\hline High school & 13 & $37 \cdot 1$ & 71 & $40 \cdot 8$ & 52 & 39.4 & 45 & $48 \cdot 4$ & 132 & $32 \cdot 4$ & 106 & $40 \cdot 8$ & 107 & 37.4 & 32 & $39 \cdot 0$ \\
\hline Post-secondary & 2 & $5 \cdot 7$ & 22 & $12 \cdot 6$ & 29 & $22 \cdot 0$ & 9 & $9 \cdot 7$ & 49 & $12 \cdot 0$ & 40 & $15 \cdot 4$ & 63 & $22 \cdot 0$ & 13 & $15 \cdot 9$ \\
\hline Married & 17 & $48 \cdot 6$ & 89 & $51 \cdot 2$ & 63 & $47 \cdot 0$ & 36 & $39 \cdot 3$ & 114 & $28 \cdot 2$ & 52 & $20 \cdot 1$ & 82 & $28 \cdot 7$ & 22 & $26 \cdot 8$ \\
\hline Income (\$US)ףף & 9768 & 9516 & 12702 & 15122 & 13500 & 19512 & 12600 & 9944 & 9846 & 7164 & 9984 & 7872 & 13224 & 15780 & 11472 & 15600 \\
\hline Unemployed & 28 & $82 \cdot 4$ & 138 & $80 \cdot 7$ & 88 & $66 \cdot 7$ & 67 & $72 \cdot 8$ & 268 & 83.5 & 197 & $87 \cdot 6$ & 181 & 71.5 & 56 & $78 \cdot 9$ \\
\hline $\begin{array}{l}\text { Language preference } \\
\text { English }\end{array}$ & & & 11 & & & & & & & & & & & & & \\
\hline Spanish & 28 & $\begin{array}{r}5 \cdot 1 \\
80 \cdot 0\end{array}$ & 124 & $\begin{array}{r}6.4 \\
71.7\end{array}$ & $\begin{array}{l}16 \\
87\end{array}$ & $\begin{array}{l}11.9 \\
64.9\end{array}$ & $\begin{array}{r}7 \\
69\end{array}$ & $\begin{array}{r}7.5 \\
74.2\end{array}$ & $\begin{array}{r}10 \\
325\end{array}$ & $\begin{array}{r}2.5 \\
81.1\end{array}$ & $\begin{array}{r}16 \\
190\end{array}$ & $\begin{array}{r}6 \cdot 2 \\
73 \cdot 9\end{array}$ & $\begin{array}{r}24 \\
203\end{array}$ & $\begin{array}{r}8.5 \\
71.7\end{array}$ & $\begin{array}{r}7 \\
59\end{array}$ & $\begin{array}{r}8 \cdot 6 \\
72 \cdot 8\end{array}$ \\
\hline Both equally & 5 & 14.3 & 38 & $22 \cdot 0$ & 31 & $23 \cdot 1$ & 17 & $18 \cdot 3$ & 69 & $16 \cdot 5$ & 51 & 19.8 & 56 & $19 \cdot 8$ & 15 & 18.5 \\
\hline Lives alone & 13 & $37 \cdot 1$ & 64 & $36 \cdot 8$ & 55 & 41.0 & 38 & $40 \cdot 9$ & 137 & $33 \cdot 7$ & 109 & $41 \cdot 8$ & 90 & 31.5 & 25 & 30.5 \\
\hline
\end{tabular}

LA, lifetime abstainer; FD, former drinker; MD, moderate drinker; HD, heavy drinker.

Data are presented as $n$ and \% except where noted.

†Sample size: income, $n 33$.

Sample size: income, $n$ 164; language preference, $n 173$.

SSample size: income, $n$ 125; education, $n 132$

ISample size: income, $n 85$; married, $n 92$.

Sample size: income, $n$ 386, married, $n$ 405; language preference, $n 401$.

† Sample size: income, $n$ 247; education, $n$ 260; married $n$ 259; working, $n$ 260; language preference, $n 257$.

t+Sample size: income, $n$ 275, language preference, $n$ 283.

§§Sample size: income, $n 75$, language preference, $n 81$

Data are presented as mean and standard deviation. 
Table 2 Health characteristics by drinking status among Puerto Rican adults ( $n$ 1472) aged 45-75 years from the Boston Puerto Rican Health Study (BPRHS) cohort, 2004-2009

\begin{tabular}{|c|c|c|c|c|c|c|c|c|c|c|c|c|c|c|c|c|}
\hline & \multicolumn{16}{|c|}{ Drinking status } \\
\hline & \multicolumn{8}{|c|}{ Men } & \multicolumn{8}{|c|}{ Women } \\
\hline & \multicolumn{2}{|c|}{ LA $(n$ 35)† } & \multicolumn{2}{|c|}{ FD $(n$ 174)‡ } & \multicolumn{2}{|c|}{$\mathrm{MD}(n 134) \S$} & \multicolumn{2}{|c|}{$\mathrm{HD}(n$ 93)\| } & \multicolumn{2}{|c|}{ LA $(n$ 407)ף } & \multicolumn{2}{|c|}{ FD (n 261)†† } & \multicolumn{2}{|c|}{ 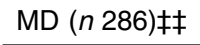 } & \multicolumn{2}{|c|}{$\mathrm{HD}(n$ 82)§§ } \\
\hline & $n$ & $\%$ & $n$ & $\%$ & $n$ & $\%$ & $n$ & $\%$ & $n$ & $\%$ & $n$ & $\%$ & $n$ & $\%$ & $n$ & $\%$ \\
\hline BMI $\left(\mathrm{kg} / \mathrm{m}^{2}\right)||||$ & 29.5 & 5.9 & $30 \cdot 2$ & 5.5 & $29 \cdot 3$ & 5.0 & $28 \cdot 8$ & 4.8 & 32.9 & $7 \cdot 2$ & 34.0 & 7.4 & $32 \cdot 1$ & $6 \cdot 0$ & $31 \cdot 1$ & 6.8 \\
\hline Overweight |ף & 27 & $77 \cdot 1$ & 143 & $82 \cdot 2$ & 113 & $84 \cdot 3$ & 73 & 78.5 & 364 & 89.4 & 239 & $91 \cdot 6$ & 255 & $89 \cdot 2$ & 69 & 84.2 \\
\hline \multicolumn{17}{|l|}{ Smoking } \\
\hline Never & 19 & $54 \cdot 3$ & 41 & $23 \cdot 6$ & 55 & $41 \cdot 0$ & 21 & $22 \cdot 8$ & 283 & 69.5 & 99 & 37.9 & 131 & $45 \cdot 8$ & 20 & 29.4 \\
\hline Former & 2 & 5.7 & 93 & 53.5 & 38 & 28.4 & 19 & 20.7 & 73 & $17 \cdot 9$ & 115 & $44 \cdot 1$ & 87 & $30 \cdot 4$ & 18 & $22 \cdot 0$ \\
\hline Current & 14 & $40 \cdot 0$ & 40 & $23 \cdot 0$ & 41 & $30 \cdot 6$ & 52 & $56 \cdot 5$ & 51 & $12 \cdot 5$ & 47 & $18 \cdot 0$ & 68 & 23.8 & 44 & $53 \cdot 7$ \\
\hline Diabetes & 12 & $36 \cdot 4$ & 80 & 47.6 & 47 & 35.9 & 33 & $36 \cdot 7$ & 170 & $42 \cdot 8$ & 117 & $46 \cdot 3$ & 94 & 33.3 & 19 & 23.5 \\
\hline Hypertension & 20 & $57 \cdot 1$ & 120 & $70 \cdot 2$ & 92 & $69 \cdot 2$ & 63 & $69 \cdot 2$ & 271 & $66 \cdot 9$ & 199 & $77 \cdot 1$ & 189 & $66 \cdot 6$ & 42 & $51 \cdot 2$ \\
\hline \multicolumn{17}{|l|}{ Medications use } \\
\hline Anticonvulsants & 2 & 5.7 & 21 & $12 \cdot 2$ & 9 & $6 \cdot 7$ & 3 & $3 \cdot 2$ & 48 & 11.8 & 29 & $11 \cdot 2$ & 19 & $6 \cdot 6$ & 2 & 2.4 \\
\hline Antidepressants & 7 & $20 \cdot 0$ & 57 & $33 \cdot 1$ & 30 & $22 \cdot 4$ & 21 & 22.6 & 147 & $36 \cdot 3$ & 114 & 43.9 & 98 & 34.3 & 42 & $51 \cdot 2$ \\
\hline Antipsychotics & 5 & $14 \cdot 3$ & 25 & 14.5 & 11 & $8 \cdot 2$ & 7 & 7.5 & 36 & 8.9 & 29 & 11.2 & 19 & $6 \cdot 6$ & 13 & 15.9 \\
\hline Anxiolytics & 3 & 8.6 & 33 & $19 \cdot 2$ & 16 & 11.9 & 9 & $9 \cdot 7$ & 108 & $26 \cdot 7$ & 83 & 31.9 & 54 & 18.9 & 21 & $25 \cdot 6$ \\
\hline Contraindicated consumption of alcohol††† & & & & & 44 & $32 \cdot 8$ & 26 & $28 \cdot 0$ & & & & & 126 & 44.1 & 48 & 58.5 \\
\hline 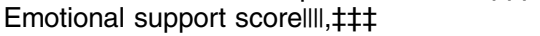 & $75 \cdot 7$ & 41.9 & 73.8 & $50 \cdot 2$ & $75 \cdot 9$ & 44.6 & 67.4 & $40 \cdot 7$ & $76 \cdot 7$ & $48 \cdot 0$ & $72 \cdot 6$ & 42.5 & $87 \cdot 8$ & 51.4 & $72 \cdot 9$ & $45 \cdot 3$ \\
\hline PAS scorelllI,§§§ & $17 \cdot 1$ & $6 \cdot 1$ & 18.5 & $7 \cdot 1$ & $20 \cdot 2$ & 7.5 & $18 \cdot 2$ & $7 \cdot 3$ & $16 \cdot 8$ & $6 \cdot 2$ & $19 \cdot 0$ & $6 \cdot 9$ & $19 \cdot 4$ & $7 \cdot 0$ & $18 \cdot 8$ & $6 \cdot 1$ \\
\hline \multicolumn{17}{|l|}{ Depressive symptomology } \\
\hline None/low (CES-D score = 0-15) & 12 & $34 \cdot 3$ & 91 & $52 \cdot 3$ & 77 & 57.9 & 42 & $45 \cdot 7$ & 149 & $37 \cdot 3$ & 77 & $29 \cdot 7$ & 111 & $37 \cdot 6$ & 24 & $29 \cdot 6$ \\
\hline Mild/moderate (CES-D score $=16-21$ ) & 6 & $17 \cdot 1$ & 30 & $17 \cdot 2$ & 20 & $13 \cdot 4$ & 15 & $16 \cdot 3$ & 62 & $15 \cdot 5$ & 34 & $13 \cdot 1$ & 48 & $16 \cdot 9$ & 14 & $17 \cdot 3$ \\
\hline High (CES-D score $\geq 22$ ) & 17 & $48 \cdot 6$ & 53 & 30.5 & 36 & $27 \cdot 1$ & 35 & 38.0 & 189 & $47 \cdot 3$ & 148 & $57 \cdot 1$ & 125 & $44 \cdot 0$ & 43 & $53 \cdot 1$ \\
\hline \multicolumn{17}{|l|}{ Perceived health status } \\
\hline Excellent/good & 6 & $17 \cdot 1$ & 73 & $42 \cdot 0$ & 61 & 45.5 & 33 & 35.5 & 97 & 23.9 & 43 & 16.5 & 96 & $33 \cdot 6$ & 24 & $29 \cdot 3$ \\
\hline Fair/poor & 29 & $82 \cdot 9$ & 101 & $58 \cdot 1$ & 73 & 54.5 & 60 & 64.5 & 310 & $76 \cdot 2$ & 217 & 83.5 & 190 & $66 \cdot 4$ & 58 & $70 \cdot 7$ \\
\hline
\end{tabular}

LA, lifetime abstainer; FD, former drinker; MD, moderate drinker; HD, heavy drinker; PAS, Psychological Acculturation Scale; CES-D, Center for Epidemiological Studies Depression Scale (ten item)

Data are presented as $n$ and \% except where noted.

†Sample size: diabetes, $n$ 33; emotional support, $n 34$.

¥Sample size: BMI, emotional support and PAS, $n$ 173; diabetes, $n$ 168; hypertension, $n$ 171; anticonvulsants, antidepressants, antipsychotics and anxiolytics, $n 172$.

§Sample size: BMI and emotional support, $n$ 132; diabetes, $n 131$; hypertension, depressive symptomology, $n 133$.

ISSample size: BMl, smoking, PAS and depressive symptomology, $n$ 92; diabetes, $n$ 90; hypertension, $n 91$.

††Sample size: BMI, emotional support $n$ 255; diabetes, $n$ 253; hypertension, PAS, $n$ 258; depressive symptomology, $n$ 259; anticonvulsants, antidepressants, antipsychotics, anxiolytics and perceived health status, $n 260$.

ł‡Sample size: BMI, $n$ 285; diabetes, $n$ 282; hypertension, depressive symptomology $n$ 284; emotional support, $n 280$.

$\S \S$ Sample size: BMl, $n$ 80; diabetes, emotional support and depressive symptomology, $n 81$.

IIIIData are presented as mean and standard deviation.

II $\mathrm{BMI} \geq 25 \mathrm{~kg} / \mathrm{m}^{2}$

t††Taking one or more medications for which alcohol is contraindicated.

łłłEmotional support score range 2-256.

§§§PAS score range $1-45$ 
Table 3 Drinking among contraindicated medication users by selected demographic and health characteristics, Puerto Rican adults ( $n$ 687) aged 45-75 years from the Boston Puerto Rican Health Study (BPRHS) cohort, 2004-2009

\begin{tabular}{|c|c|c|c|}
\hline & \multicolumn{2}{|c|}{ Drinks alcohol } & \multirow[b]{2}{*}{$P$ value } \\
\hline & $\%$ & $n$ & \\
\hline Gender & & & 0.010 \\
\hline Female & $32 \cdot 8$ & 172 & \\
\hline Male & 44.2 & 68 & \\
\hline Education level & & & 0.183 \\
\hline Elementary/middle & 31.9 & 101 & \\
\hline High school & 37.5 & 99 & \\
\hline Post-secondary & 40.6 & 39 & \\
\hline Marital status & & & 0.798 \\
\hline Unmarried & $35 \cdot 2$ & 173 & \\
\hline Married & $36 \cdot 2$ & 67 & \\
\hline Employment & & & 0.047 \\
\hline Employed & $50 \cdot 0$ & 26 & \\
\hline Unemployed & $36 \cdot 1$ & 193 & \\
\hline Language preference & & & 0.000 \\
\hline English & 60.5 & 26 & \\
\hline Spanish & $35 \cdot 6$ & 176 & \\
\hline Both equally & $27 \cdot 3$ & 36 & \\
\hline Diabetes status & & & 0.019 \\
\hline No diabetes & 39.0 & 144 & \\
\hline Diabetes & 30.2 & 88 & \\
\hline Depressive symptomology† & & & 0.330 \\
\hline No & 38.6 & 64 & \\
\hline Yes & 34.4 & 174 & \\
\hline Overweightł & & & 0.894 \\
\hline Yes & $35 \cdot 3$ & 214 & \\
\hline No & $36 \cdot 1$ & 26 & \\
\hline Living situation & & & 0.664 \\
\hline Lives alone & 34.4 & 88 & \\
\hline Lives with someone else & $36 \cdot 0$ & 152 & \\
\hline Hypertension & & & 0.457 \\
\hline Yes & 34.5 & 156 & \\
\hline No & 37.4 & 82 & \\
\hline
\end{tabular}

†CES-D score $\geq 16$ (Center for Epidemiological Studies Depression Scale, ten item) is considered as depressive symptomology. $\ddagger \mathrm{BMI} \geq 25 \mathrm{~kg} / \mathrm{m}^{2}$.

have higher rates of substance abuse than women ${ }^{(10)}$. These findings are consistent with findings from the National Institutes of Health and the Hispanic Americans Baseline Alcohol Survey (HABLAS), which found that Puerto Rican men and women (18+ years) had higher risk of alcohol abuse than the general US population or other Hispanic subgroups ${ }^{(3,18)}$. Similar to studies that included Puerto Ricans ${ }^{(3,29,30)}$, women in the present BPRHS cohort reported lower alcohol consumption than men.

Women with higher incomes were more likely to be moderate drinkers than abstainers. Women with diabetes were more likely to be moderate than heavy drinkers. Women with higher BMI were more likely to abstain than drink moderately. With greater emotional support, women were more likely to be moderate than former drinkers; and with greater psychological acculturation, women were more likely to be moderate drinkers than abstainers. As heavy drinking appears to increase with acculturation for women, public health initiatives are needed to support appropriate alcohol use, particularly among women with chronic illnesses.

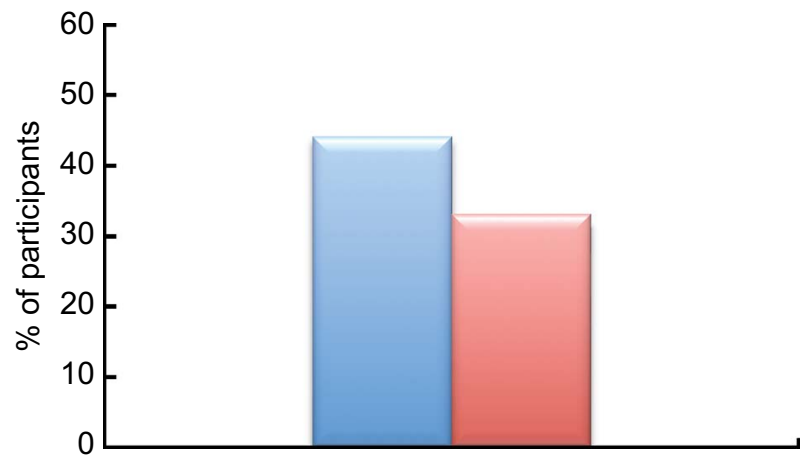

Fig. 1 (colour online) Percentage of participants ( $\mathrm{M}$, men; $\square$, women) consuming alcohol while taking medications with alcohol contraindications among Puerto Rican adults ( $n$ 687) aged 45-75 years from the Boston Puerto Rican Health Study (BPRHS) cohort, 2004-2009

Previous studies have found associations between acculturation and drinking for women and our findings are consistent with this ${ }^{(31)}$. Lara et al. previously suggested that acculturation may affect Hispanics' health in a negative way ${ }^{(32)}$. It has been proposed that acculturation has a general effect of liberalizing norms and attitudes towards drinking ${ }^{(34)}$. Similar to other studies including Hispanic populations in the $\mathrm{USA}^{(14,33-38)}$, linguistic acculturation level tended to be higher with heavy drinking in women. In the present study, participants who spoke English as a primary language, an indicator of higher acculturation, were more likely to be heavy drinkers. However, the association was not significant after adjusting for other demographic and behavioural characteristics. These results may partly be due to the small number of English-speaking participants in this sample.

Contributions of the study include its focus on Puerto Ricans. Hispanic groups are often combined together in research, but the current study exclusively examined a large proportion (about $15 \%$ ) of the Puerto Ricans living in the Boston area ${ }^{(22)}$. This is a growing population that is seldom studied. Also, the study looked at heavy drinking among middle-aged and older adults, a relatively novel field of research that will continue to grow in importance because of the rapidly ageing population in the USA. To the best of the authors' knowledge, no previous study has looked at the drinking patterns of Puerto Rican adults using medications with alcohol contraindication.

Several important individual-level characteristics were considered in the analysis. However, this does not eliminate the possibility of residual confounding. As with all other cross-sectional studies, the present study cannot provide evidence of temporality of associations and, consequently, causation. Depressive symptomatology was used instead of clinically diagnosed depression. However, the CES-D is a widely used and validated self-report depression scale for research that has shown consistency, validity and reliability in older adults and Puerto Ricans ${ }^{(22)}$. It is likely that the small number of heavy drinkers may 
Table 4 Multinomial logistic regression of characteristics associated with drinking status among Puerto Rican men ( $n$ 381) aged 45-75 years from the Boston Puerto Rican Health Study (BPRHS) cohort, 2004-2009†

\begin{tabular}{|c|c|c|c|c|c|c|}
\hline & \multicolumn{2}{|c|}{ LA } & \multicolumn{2}{|c|}{ FD } & \multicolumn{2}{|c|}{$\mathrm{HD}$} \\
\hline & RRR $\ddagger$ & $95 \% \mathrm{Cl}$ & RRR $\ddagger$ & $95 \% \mathrm{Cl}$ & RRR $\ddagger$ & $95 \% \mathrm{Cl}$ \\
\hline Age (years) & $0.92^{\star *}$ & $0.86,0.98$ & 0.97 & $0.94,1.01$ & $0.94^{\star *}$ & $0.90,0.98$ \\
\hline \multicolumn{7}{|l|}{ Education level } \\
\hline Elementary/middle & \multicolumn{2}{|c|}{1.00} & \multicolumn{2}{|c|}{1.00} & \multicolumn{2}{|c|}{1.00} \\
\hline High school & 0.46 & $0.16,1.33$ & 0.82 & $0.43,1.55$ & 1.06 & $0.51,2.21$ \\
\hline Post-secondary & 0.23 & $0.04,1.29$ & 0.48 & $0.20,1.15$ & 0.49 & $0.16,1.48$ \\
\hline \multicolumn{7}{|l|}{ Marital status } \\
\hline Unmarried & \multicolumn{2}{|c|}{1.00} & \multicolumn{2}{|c|}{1.00} & \multicolumn{2}{|c|}{1.00} \\
\hline Married & 0.76 & $0.29,2.00$ & 0.81 & $0.45,1.43$ & 0.97 & $0.49,1.92$ \\
\hline Income (\$US)§ & 0.98 & $0.95,1.02$ & 1.00 & $0.98,1.01$ & $0.98^{*}$ & $0.96,0.99$ \\
\hline \multicolumn{7}{|l|}{ Employment } \\
\hline Employed & \multicolumn{2}{|c|}{1.00} & \multicolumn{2}{|c|}{1.00} & \multicolumn{2}{|c|}{1.00} \\
\hline Unemployed & 0.54 & $0.12,2 \cdot 33$ & 0.87 & $0.39,1.97$ & 1.25 & $0.51,3.08$ \\
\hline \multicolumn{7}{|l|}{ Language preference } \\
\hline English & \multicolumn{2}{|c|}{1.00} & \multicolumn{2}{|c|}{1.00} & \multicolumn{2}{|c|}{1.00} \\
\hline Spanish & 0.85 & $0.14,5 \cdot 13$ & 1.49 & $0.51,4.33$ & $2 \cdot 21$ & $0.58,8.46$ \\
\hline Both equally & 1.08 & $0.16,7 \cdot 29$ & 1.39 & $0.47,4.15$ & 1.47 & $0.36,5.99$ \\
\hline \multicolumn{7}{|l|}{ Diabetes status } \\
\hline No diabetes & \multicolumn{2}{|c|}{1.00} & \multicolumn{2}{|c|}{1.00} & \multicolumn{2}{|c|}{1.00} \\
\hline Diabetes & $2 \cdot 08$ & $0 \cdot 70,6 \cdot 13$ & 1.60 & $0.85,2.99$ & 1.78 & $0.84,3.76$ \\
\hline Emotional support scorell & 1.02 & $0.93,1.13$ & 1.02 & $0.96,1.08$ & 0.99 & $0.92,1.06$ \\
\hline PAS scoreף & 0.95 & $0.88,1.02$ & 0.97 & $0.93,1.02$ & 0.97 & $0.92,1.02$ \\
\hline \multicolumn{7}{|l|}{ Medication use†† } \\
\hline Yes & \multicolumn{2}{|c|}{1.00} & \multicolumn{2}{|c|}{1.00} & \multicolumn{2}{|c|}{1.00} \\
\hline No & 1.45 & $0.49,4.33$ & $0.56^{*}$ & $0.33,0.98$ & $1 \cdot 83$ & $0.83,4.02$ \\
\hline BMI $\left(\mathrm{kg} / \mathrm{m}^{2}\right)$ & 0.98 & $0.89,1.09$ & 0.99 & $0.93,1.05$ & 0.98 & $0.91,1.05$ \\
\hline
\end{tabular}

LA, lifetime abstainer; FD, former drinker; HD, heavy drinker; RRR, relative risk ratio; PAS, Psychological Acculturation Scale.

${ }^{*} P<0.05,{ }^{* \star} P<0.01$.

†Moderate drinking (MD) was used as the reference category.

flndicates the ratio of the probability of choosing one outcome category over the probability of choosing the baseline category.

§Per 1000 \$US.

IIEmotional support score range 2-256.

IPAS score range $1-45$.

††Taking one or more medications for which alcohol is contraindicated.

have decreased the precision and estimation of parameters included in the analysis. Drinking behaviour was based on self-report. This is a limitation of most research examining health risk behaviours. The questionnaire for alcohol consumption has not been tested for reliability and validity in this population. Nevertheless, the questions used are very similar to the kinds of questions used frequently in alcohol research (i.e. quantity/frequency). Also, we were unable to define binge drinking in terms of number of drinks in a given time period because the questionnaire only asked participants how many drinks they consumed in a typical day. Under-reporting of alcohol intake may be more common among heavy drinkers ${ }^{(39)}$ and this may have affected the results ${ }^{(39-41)}$. Future studies should use both recent recall and measures of longer-term drinking patterns to minimize the likelihood of under-reporting. The limited sampling approaches and areas (i.e. Boston metropolitan area) used for recruitment may have reduced representativeness, and therefore generalizability of the results. Nevertheless, given that the study sample represents a large proportion of the Puerto Ricans in this age range living in the recruitment area, the results should be reasonably generalizable to similar communities of Puerto Rican adults living in high-density urban areas in the USA. Despite these limitations, the study findings appear to be sound and to accurately represent the population characteristics associated with heavy drinking. These results may be used for future studies and for designing interventions in similar communities of Puerto Rican adults living in high-density urban areas in the USA.

Although cause-and-effect relationships should not be inferred from associations, these findings suggest some provocative areas for both research and intervention. More research about medication regimens with alcohol contraindications and drinking levels in this population is needed. Contraindication information should be made clear to patients prescribed such medication, to avoid adverse alcohol-medication effects. It is important that physicians and patients discuss alcohol consumption as a component of illness management and medication use. Further research could explore the areas where there is miscommunication regarding the dangers of mixing medications with alcohol, especially among populations with high medication use.

Puerto Ricans are the second largest subgroup within the fastest growing minority group in the USA, and current drinking levels differ among men and women. The relationship between gender and heavy drinking should be 
Table 5 Multinomial logistic regression of characteristics associated with drinking status among status among Puerto Rican women ( $n$ 911) aged 45-75 years from the Boston Puerto Rican Health Study (BPRHS) cohort, 2004-2009†

\begin{tabular}{|c|c|c|c|c|c|c|}
\hline & \multicolumn{2}{|c|}{ LA } & \multicolumn{2}{|c|}{ FD } & \multicolumn{2}{|c|}{ HD } \\
\hline & RRR $\ddagger$ & $95 \% \mathrm{Cl}$ & $\mathrm{RRR} \ddagger$ & $95 \% \mathrm{Cl}$ & RRR $\ddagger$ & $95 \% \mathrm{Cl}$ \\
\hline $\begin{array}{l}\text { Age (years) } \\
\text { Education level }\end{array}$ & $1.03^{*}$ & $1.00,1.06$ & $1.04^{\star \star}$ & $1.01,1.07$ & $0.95^{\star}$ & $0.90,0.99$ \\
\hline Elementary/middle & \multicolumn{2}{|c|}{1.00} & \multicolumn{2}{|c|}{1.00} & \multicolumn{2}{|c|}{1.00} \\
\hline High school & 0.97 & $0.63,1.53$ & 1.34 & $0.83,2.18$ & 0.90 & $0.44,1.82$ \\
\hline Post-secondary & 0.61 & $0.33,1.12$ & 0.95 & $0.50,1.82$ & 0.58 & $0.22,1.56$ \\
\hline Marital status & & & \multirow{2}{*}{\multicolumn{2}{|c|}{1.00}} & \multirow{2}{*}{\multicolumn{2}{|c|}{1.00}} \\
\hline Unmarried & \multicolumn{2}{|c|}{1.00} & & & & \\
\hline Married & 1.01 & $0.65,1.58$ & 1.51 & $0.91,2.51$ & 1.52 & $0.73,3.15$ \\
\hline Income (\$US)§ & $0.98^{* *}$ & $0.96,1.00$ & $0.98^{*}$ & $0.97,0.99$ & 1.00 & $0.99,1.02$ \\
\hline Employment & \multirow{2}{*}{\multicolumn{2}{|c|}{1.00}} & \multirow{2}{*}{\multicolumn{2}{|c|}{1.00}} & & \\
\hline Employed & & & & & \multicolumn{2}{|c|}{1.00} \\
\hline Unemployed & 1.04 & $0.59,1.84$ & 0.75 & $0.39,1.44$ & 0.67 & $0.28,1.59$ \\
\hline Language preference & & & \multirow{2}{*}{\multicolumn{2}{|c|}{1.00}} & \multirow{2}{*}{\multicolumn{2}{|c|}{1.00}} \\
\hline English & \multicolumn{2}{|c|}{1.00} & & & & \\
\hline Spanish & 1.69 & $0.54,5.25$ & 1.20 & $0.43,3.37$ & 0.71 & $0.20,2.56$ \\
\hline Both equally & $2 \cdot 67^{\star}$ & $1.00,7 \cdot 11$ & 1.50 & $0.54,4.19$ & 0.81 & $0.23,2.84$ \\
\hline Diabetes status & & & \multirow{2}{*}{\multicolumn{2}{|c|}{1.00}} & \multirow{2}{*}{\multicolumn{2}{|c|}{1.00}} \\
\hline No diabetes & \multicolumn{2}{|c|}{1.00} & & & & \\
\hline Diabetes & 1.31 & $0.83,2.08$ & 1.15 & $0.70,1.88$ & 0.52 & $0.26,1.04$ \\
\hline $\begin{array}{l}\text { Emotional support } \\
\text { scorell }\end{array}$ & 0.97 & $0.93,1.01$ & $0.94^{*}$ & $0.90,0.99$ & 0.97 & $0.91,1.03$ \\
\hline $\begin{array}{l}\text { PAS scoreף } \\
\text { Medication usett }\end{array}$ & $0.95^{\star \star}$ & $0.92,0.98$ & 0.99 & $0.96,1.03$ & 0.98 & $0.93,1.0$ \\
\hline Yes & \multicolumn{2}{|c|}{1.00} & \multicolumn{2}{|c|}{1.00} & \multicolumn{2}{|c|}{1.00} \\
\hline No & 1.04 & $0.69,1.57$ & $0.67^{\star}$ & $0.45,0.97$ & $0.56^{\star}$ & $0.30,0.95$ \\
\hline BMI $\left(\mathrm{kg} / \mathrm{m}^{2}\right)$ & 1.03 & $1.00,1.07$ & $1.04^{\star \star}$ & $1.01,1.07$ & 0.96 & $0.91,1.01$ \\
\hline
\end{tabular}

LA, lifetime abstainer; FD, former drinker; HD, heavy drinker; RRR, relative risk ratio; PAS, Psychological Acculturation Scale.

${ }^{\star} P<0.05,{ }^{\star \star} P<0.01$.

†Moderate drinking (MD) was used as the reference category.

fIndicates the ratio of the probability of choosing one outcome category over the probability of choosing the baseline category.

§Per 1000 \$US.

IIEmotional support score range 2-256.

IPAS score range $1-45$.

††Taking one or more medications for which alcohol is contraindicated.

further explored, as it is expected that the disparity between men's and women's drinking rates will decrease in the coming years ${ }^{(42)}$. Changing societal roles and attitudes towards women may influence drinking patterns and change the drinking culture as a whole. Research efforts should explore gender patterns regarding permissiveness to drink alcohol in Puerto Rican communities around the USA. Factors such as changing societal roles for women and the elderly could be included. More studies need to establish causal links to better identify risk factors and subsequently design better-quality intervention programmes for this population. It is important to replicate studies in other ethnic groups to understand the underlying distinctions between risk factors for heavy drinking among rapidly increasing Hispanic subgroups.

\section{Acknowledgements}

Financial support: This work was supported by the National Institutes of Health (NIH) (grant numbers P01 AG023394 and P50 HL105185). The NIH had no role in the design, analysis or writing of this article. Conflict of interest: None. Authorship: J.Y.A.C. and R.F.H. analysed and interpreted the data and wrote the manuscript; K.L.T. and L.M.F. designed the study and edited the manuscript; C.S.L. helped to conceptualize the analysis and to write the manuscript. All authors read and approved the final manuscript. Ethics of buman subject participation: The Institutional Review Board at the Tufts Medical Center approved all procedures involving human subjects. Permission to use the data was granted by the Institutional Review Board at Northeastern University.

\section{References}

1. World Health Organization (2011) Action needed to reduce health impact of harmful alcohol use. http://www.who. int/mediacentre/news/releases/2011/alcohol_20110211/en/ (accessed April 2013).

2. Centers for Disease Control and Prevention (2010) Alcohol and Public Health: Fact Sheet. http://www.cdc.gov/alcohol/ fact-sheets/alcohol-use.htm (accessed April 2013).

3. National Institute on Alcohol Abuse and Alcoholism (2012) Ethnicity and Health Disparities in Alcohol Research. http:// pubs.niaaa.nih.gov/publications/arh40/152-160.htm (accessed April 2013).

4. US Department of Health and Social Services, Substance Abuse and Mental Health Services Administration (2010) Results from the 2009 National Survey on Drug Use and Health: Volume I. Summary of National Findings. http:// 
www.oas.samhsa.gov/NSDUH/2k9NSDUH/2k9Results.htm (accessed April 2013).

5. National Institutes of Health (2010) Healthy People 2010: Substance Abuse. http://www.healthypeople.gov/ document/HTML/Volume2/26Substance.htm (accessed April 2013).

6. Kirchner JE, Zubritsky C, Cody M et al. (2007) Alcohol consumption among older adults in primary care. $J$ Gen Intern Med 22, 92-97.

7. Naimi TS, Brewer RD, Mokdad A et al. (2003) Binge drinking among US adults. JAMA 289, 70-75.

8. Hallgren M, Högberg P \& Andréasson S (2009) Health effects, consumption trends and related issues. Presented at the Expert Conference on Alcohol and Health, Stockholm, Sweden, 21-22 September 2009.

9. Huntgeburth M, Ten Freyhaus H \& Rosenkranz S (2005) Alcohol consumption and hypertension. Curr Hypertens Rep 7, 180-185.

10. Parsons OA \& Nixon SJ (1993) Neurobehavioral sequelae of alcoholism. Neurol Clin 11, 205-218.

11. Epstein EE, Fischer-Elber K \& Al-Otaiba Z (2007) Women, aging, and alcohol use disorders. J Women Aging 19, 31-48.

12. Sacco RL, Elkind M, Boden-Albala B et al. (1999) The protective effect of moderate alcohol consumption on ischemic stroke. JAMA 281, 53-60.

13. National Institute on Alcohol Abuse and Alcoholism (1998) Alcohol Alert No. 40: Alcohol and Aging. http://pubs.niaaa. nih.gov/publications/aa40.htm (accessed April 2013).

14. Weathermon R \& Crabb DW (1999) Alcohol and medication interactions. Alcohol Res Health 23, 40-54.

15. Alegria M, Canino G, Shrout PE et al. (2008) Prevalence of mental illness in immigrant and non-immigrant US Latino groups. Am J Psychiatry 165, 359-369.

16. Caetano R (1988) Alcohol use among Hispanic groups in the United States. Am J Drug Alcohol Abuse 14, 293-308.

17. Caetano R, Raimisetty-Mikler S \& Rodriguez LA (2008) The Hispanic Americans Baseline Alcohol Survey (HABLAS): rates and predictors of DUI across Hispanic national groups. Accid Anal Prev 40, 733-741.

18. Caetano R, Raimisetty-Mikler S \& Rodriguez LA (2008) The Hispanic Americans Baseline Alcohol Survey (HABLAS): rates and predictors of alcohol abuse and dependence across Hispanic national groups. I Stud Alcohol Drugs 69, 441-448.

19. Caetano R, Ramisetty-Mikler S \& Rodriguez LA (2009) The Hispanic Americans Baseline Alcohol Survey (HABLAS): the association between birthplace, acculturation and alcohol abuse and dependence across Hispanic national groups. Drug Alcohol Depend 99, 215-221.

20. Guarnaccia PJ, Martinez-Pincay I, Alegria M et al. (2007) Assessing diversity among Latinos: results from the NLAAS. Hisp J Behav Sci 29, 510-534.

21. Dawson DA (1998) Beyond Black, White and HIspanic: race, ethnic origin and drinking patterns in the United States. J Subst Abuse 10, 321-339.

22. Tucker KL, Mattei J, Noel SE et al. (2010) The Boston Puerto Rican Health Study, a longitudinal cohort study on health disparities in Puerto Rican adults: challenges and opportunities. BMC Public Health 10, 107.

23. National Institute on Alcohol Abuse and Alcoholism (2013) Moderate and Binge Drinking. http://www.niaaa.nih.gov/ alcohol-health/overview-alcohol-consumption/moderatebinge-drinking (accessed May 2013).

24. Lin H, Bermudez OI, Falcon LM et al. (2002) Hypertension among Hispanic elders of a Caribbean origin in Massachusetts. Ethn Dis 12, 499-507.
25. Tucker KL, Bermudez OI \& Castaneda C (2000) Type 2 diabetes is prevalent and poorly controlled among Hispanic elders of Caribbean origin. Am J Public Health 90, 1288-1293.

26. Kohout FJ, Berkman LF, Evans DA et al. (1993) Two shorter forms of the CES-D (Center for Epidemiological Studies Depression) depression symptoms index. J Aging Health $\mathbf{5}$, 179-193.

27. Merrick EL, Horgan CM, Hodgkin D et al. (2008) Unhealthy drinking patterns in older adults: prevalence and associated characteristics. J Am Geriatr Soc 56, 214-223.

28. Moore AA, Hays RD, Greendale GA et al. (1999) Drinking habits among older persons: findings from the NHANES I Epidemiologic Followup Study (1982-84). National Health and Nutrition Examination Survey. J Am Geriatr Soc 47, 412-416.

29. Randolph WM, Stroup-Benham C, Black SA et al. (1998) Alcohol use among Cuban-Americans, Mexican-Americans, and Puerto Ricans. Alcohol Health Res World 22, 265-269.

30. Black SA \& Markides KS (1993) Acculturation and alcohol consumption in Puerto Rican, Cuban-American, and Mexican-American women in the United States. Am J Public Health 83, 890-893.

31. Zemore SE (2007) Acculturation and alcohol among Latino adults in the United States: a comprehensive review. Alcohol Clin Exp Res 31, 1968-1990.

32. Lara M, Gamboa C, Kahramanian MI et al. (2005) Acculturation and Latino health in the United States: a review of the literature and its sociopolitical context. Annu Rev Public Health 26, 367-397.

33. Caetano R, Ramisetty-Mikler S, Wallisch LS et al. (2008) Acculturation, drinking, and alcohol abuse and dependence among Hispanics in the Texas-Mexico border. Alcobol Clin Exp Res 32, 314-321.

34. Alaniz ML, Treno AJ \& Saltz RF (1999) Gender, acculturation, and alcohol consumption among Mexican Americans. Subst Use Misuse 34, 1407-1426.

35. Marin G \& Posner SF (1995) The role of gender and acculturation on determining the consumption of alcoholic beverages among Mexican-Americans and Central Americans in the United States. Int J Addict 30, 779-794.

36. Markides KS, Ray LA, Stroup-Benham CA et al. (1990) Acculturation and alcohol consumption in the Mexican American population of the southwestern United States: findings from HHANES 1982-84. Am J Public Health 80, Suppl. VII, 42-46.

37. Neff JA \& Hoppe SK (1992) Acculturation and drinking patterns among US Anglos, blacks, and Mexican Americans. Alcobol Alcohol 27, 293-308.

38. Zemore SE (2005) Re-examining whether and why acculturation relates to drinking outcomes in a rigorous, national survey of Latinos. Alcohol Clin Exp Res 29, 2144-2153.

39. Poikolainen $\mathrm{K}$ (1985) Underestimation of recalled alcohol intake in relation to actual consumption. Br J Addict 80, 215-216.

40. Bloomfield K, Stockwell T, Gmel G et al. (2003) International Comparisons of Alcohol Consumption. http://pubs. niaaa.nih.gov/publications/arh27-1/95-109.htm (accessed November 2013)

41. Laatikainen T, Manninen L, Poikolainen K et al. (2003) Increased mortality related to heavy alcohol intake pattern. J Epidemiol Community Health 57, 379-384.

42. Del Rio MC, Prada C \& Alvarez FJ (1996) The use of medication and alcohol among the Spanish population. $\mathrm{BrJ}$ Clin Pharmacol 41, 253-255. 